\title{
Automated Screening for Genomic Imbalances using Matrix-Based Comparative Genomic Hybridization
}

\author{
Swen Wessendorf, Björn Fritz, Gunnar Wrobel, Michelle Nessling, Stefan Lampel, \\ Daniel Göettel, Manfred Küepper, Stefan Joos, Ton Hopman, Felix Kokocinski, \\ Hartmut Döhner, Martin Bentz, Carsten Schwäenen, and Peter Lichter
}

\author{
Division Organisation komplexer Genome (SW, BF, GW, MN, SL, DG, MK, SJ, FK, CS, PL), Deutsches \\ Krebsforschungszentrum, Heidelberg; Division Innere Medizin III (SW, HD, MB), Medizinische Klinik der Universität \\ Ulm, Germany; and Department of Pathology (TH), University of Maastricht, The Netherlands
}

\begin{abstract}
SUMMARY: Genome-wide screening for chromosomal imbalances using comparative genomic hybridization (CGH) revealed a wealth of data on previously unrecognized tumor-specific genomic alterations. CGH to microarrays of DNA, an approach termed matrix-CGH, allows detection of genomic imbalances at a much higher resolution. We show that matrix CGH is also feasible from small tissue samples requiring universal amplification of genomic DNA. Because widespread application of matrix-CGH experiments using large numbers of DNA targets demands a high degree of automation, we have developed a protocol for a fully automated procedure. The use of specialized instrumentation for the generation of DNA chips, their hybridization, scanning, and evaluation required numerous alterations and modifications of the initial protocol. We here present the elaboration and testing of automated matrix-CGH. A chip consisting of 188 different genomic DNA fragments, cloned in bacterial artificial chromosome (BAC) or P1-derived artificial chromosome (PAC) vectors and immobilized in replicas of 10, was used to assess the performance of the automated protocol in determining the gene dosage variations in tumor cell lines COLO320-HSR, HL60, and NGP. Although ratios of matrix-CGH were highly concordant with results of chromosomal CGH (85\%), the dynamic range of the matrix-CGH ratios was highly superior. Investigation of the two amplicons on 8q24 in COLO320-HSR and HL60, containing the MYC gene, revealed a homogeneous amplicon in COLO320-HSR but a heterogeneous amplification pattern in HL60 cells. Although control clones for normalization of the signal ratios can be predicted in cases with defined chromosomal aberrations, in primary tumors such data are often not available, requiring alternative normalization algorithms. Testing such algorithms in a primary high-grade B-cell lymphoma, we show the feasibility of this approach. With the matrix-CGH protocol presented here, robust and reliable detection of genomic gains and losses is accomplished in an automated fashion, which provides the basis for widespread application in tumor and clinical genetics. (Lab Invest 2002, 82:47-60).
\end{abstract}

A nalysis of chromosomal imbalances by comparative genomic hybridization (CGH) (Du Manoir et al, 1993; Joos et al, 1993; Kallioniemi et al, 1992) has greatly contributed to the current knowledge of genomic alterations associated with constitutional and sporadic genetic diseases (Forozan et al, 1997; Knuutila et al, 1998, 1999; Zitzelsberger et al, 2001). Most applications have dealt with the identification of recurrent genetic alterations in tumor cell populations. Such studies have not only provided a basis for the identification of genes relevant for the pathogenesis of a given tumor entity (Joos et al, 1996, 2000; Koivisto et al, 1997; Monni et al, 1996; Weber et al, 2000), but have also contributed to recently developed tumor classification schemes (see eg, Bentz et al, 2001; Joos et al, 1996). However, a more widespread exploitation

Received September 24, 2001.

Both Swen Wessendorf and Björn Fritz contributed equally to this work. This work was supported by grants from the Bundesministerium fir Bildung und Forschung (BMBF, FKZ 01 KW 9937), the Deutsche Krebshilfe (No. 70-2312 Be2), and IZKF C12 and the Land Thüringen.

Address reprint requests to: Dr. Peter Lichter, Division Organisation komplexer Genome, Deutsches Krebsforschungszentrum, Im Neuenheimer Feld 280,D-69120, Heidelberg, Germany.E-mail:p.lichter@dkfz.de of CGH has been hampered by methodological restrictions, which are mainly caused by the use of metaphase chromosome preparations as hybridization targets: (a) the resolution achievable by chromosomal CGH is restricted to about 3 to $10 \mathrm{Mb}$ for low copy number losses and gains such as partial monosomies and trisomies (Bentz et al, 1998; Kirchhoff et al, 1999); and (b) the necessity to assess large numbers of chromosomes in each experiment has impeded the development of fully automated evaluation procedures, prohibiting broad implementation of CGH in routine diagnostic settings.

To overcome the limitations of CGH to chromosomal targets, a novel approach has been developed, termed matrix-CGH (Solinas-Toldo et al, 1997). For matrix-CGH, chromosome preparations are substituted by sets of well-defined genomic DNA fragments microarrayed on solid support to serve as hybridization targets (Fig. 1). Thus, genomic imbalances are detected with much higher resolution, allowing copy number changes to be associated with individual loci and genomic markers (Heiskanen et al, 2000; Pinkel et al, 1998; Pollack et al, 1999; Solinas-Toldo et al, 1997). This approach is much more demanding than the widespread application of DNA-microarrays for the 

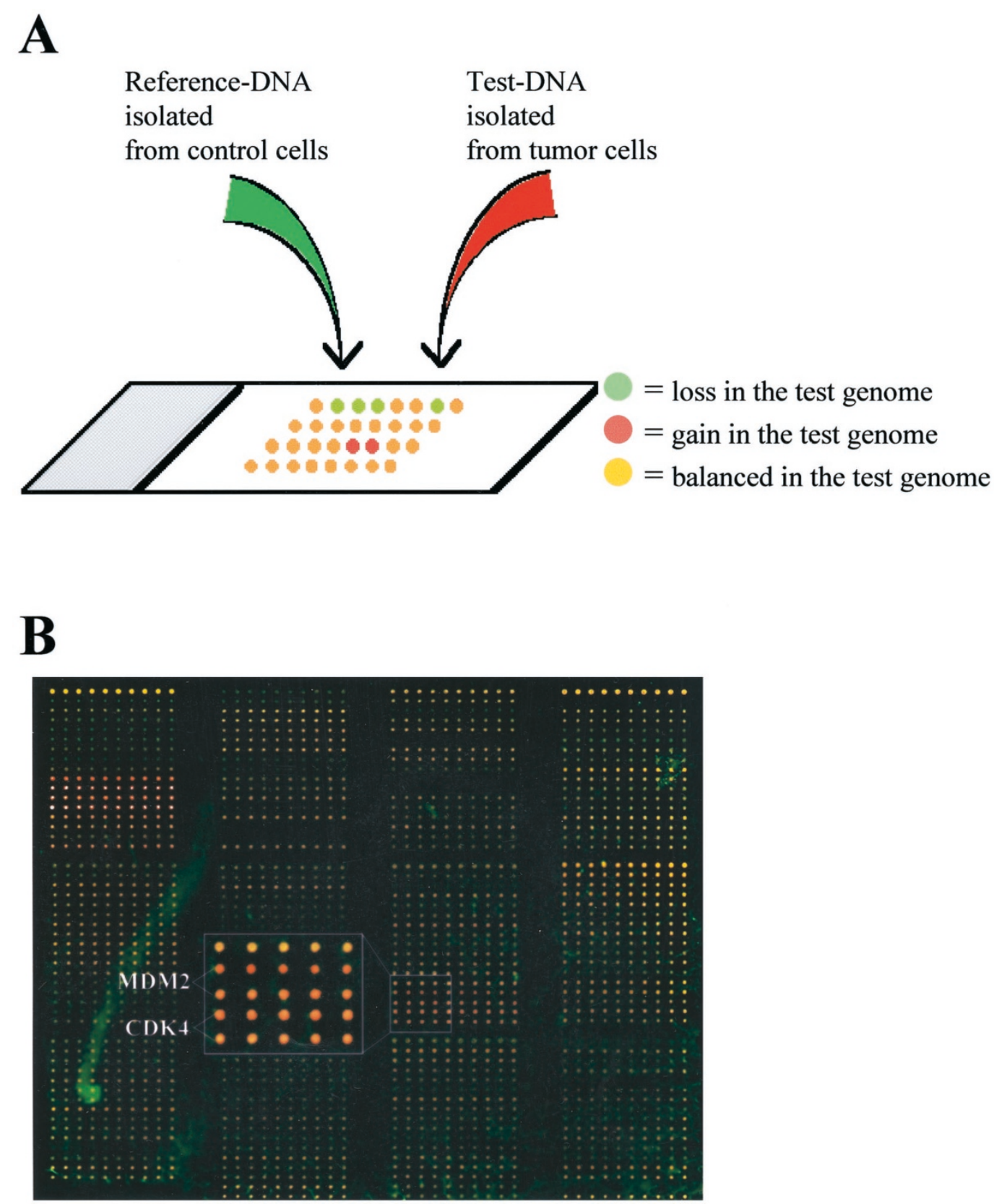

Figure 1.

A, Schematic representation of matrix-comparative genomic hybridization (matrix-CGH). Differently labeled test and control DNA are cohybridized to a matrix consisting of microarrayed DNA fragments; DNA copy number changes in the test genome are scored by the ratio of the two signals on each spot. B, Example of a matrix-CGH experiment with target fragments arranged in replicas of 10. The inset depicts a section indicating amplification of the MDM2 and CDK4 genes by the dominance of the red test genome signal.

detection of gene expression patterns because (a) it requires the reliable detection of subtle differences in the fluorescence ratios of test and control genomes, for example, diagnosis of alterations can rely on ratio differences smaller than 0.1 (Lichter et al, 2000; Weber et al, 2000); and (b) the complexity of the labeled total genomic DNA probe sequence pool is several orders of magnitude higher than that of a cDNA pool. These requirements can be met using genomic DNA fragments cloned in Bacterial, P1-Derived, or Yeast Artificial Chromosome (BAC, PAC, YAC) vectors (Pinkel et al, 1998; Solinas-Toldo et al, 1997). The successful use of cDNA microarrays for matrix-CGH has also been reported (Pollack et al, 1999). However, reliable diagnosis of a genomic imbalance by cDNA chips relies on the integration of signal ratios from separate cDNAs, whose genes are localized within the respective region.

Since the original publication of matrix-CGH (Solinas-Toldo et al, 1997), we have elaborated the automation of this approach by testing a large variety of instrumental solutions, each requiring a number of distinct changes of the matrix-CGH protocol. We here report on the procedure that emerged from these 
extensive tests and developments and currently allows a robust high through-put screening for genomic imbalances. Methodological aspects, as well as different statistical evaluation procedures, are discussed in detail. The potential of the technique is demonstrated using established tumor cell lines as well as primary tumor specimens of different origin and quality. This includes the analysis of small tissue samples requiring representative amplification of minute amounts of genomic DNA.

\section{Results}

Fine Analysis of Gene Amplifications in Small Tumor Samples using Matrix-CGH in Combination with Universal PCR

Analysis of genomic alterations in tumor tissue often relies on small amounts of sample material, from which only minute amounts of genomic DNA can be prepared. Thus, for a widespread application of matrix-CGH in tumor genetics, it is necessary to reliably detect chromosomal imbalances also in enzymatically amplified DNA. Therefore, we investigated the potential of matrix-CGH using universally amplified genomic DNA from three tumor cell samples (see Fig. 2): the leiomyosarcoma LMS-2, the mediastinal B-cell lymphoma PMBL-16, the primary Hodgkin's lymphoma cHL-10 from which about 30 malignant cells (the Hodgkin- and Reed-Sternberg cells) were collected by microdissection, and a Hodgkin's lymphoma-derived cell line HDLM-2 for control. In all cases distinct amplifications on the short arm of chromosome 9 affecting band 9p24 had been identified by chromosomal $\mathrm{CGH}$. The gene coding for tyrosine kinase JAK2 is localized on 9p24 and is thus possibly affected by these amplifications. For matrix-CGH, a series of some 25 PAC clones from different chromosomal locations were immobilized on glass slides along with two PAC clones (clones 64, 65) covering the JAK2 gene. In all cases analyzed, a significant increase of the signal ratio was measured on the respective JAK2 targets compared with the set of control clones $(p<0.05$; Fig. 2). Because copy number gain of JAK2 was diagnosed in all cases, matrix-CGH allows detection of chromosomal imbalances even in tumor samples where the source material is small or the DNA is of low quality, prohibiting alternative approaches like interphase FISH and Southern blot analysis.

\section{Optimized Matrix-CGH Procedure for the Analysis of Tumor Genomes}

DNA Microarray With Multiple Genes of Oncogenic Function. To detect multiple chromosomal imbalances in a tumor sample by a single DNA-chip, 188 PAC and $\mathrm{BAC}$ clones were selected to represent genomic fragments of interest in malignant neoplasms. These included clones containing DNA inserts with known oncogenes and tumor suppressor genes, as well as fragments from suspect chromosomal regions that were previously found to be recurrently aberrant in FISH or chromosomal CGH analyses. As detailed in "Materials and Methods," the clones were isolated by filter hybridization with cDNA probes or via database searches. The list of clones can be found at http:// www.dkfz-heidelberg.de/kompl_genome/index.html.

The protocol applied in these studies was based on multiple modifications of the initial procedure (SolinasToldo et al, 1997), affecting the following steps: probe labeling, pretreatment of slides, hybridization conditions, and implementation of two-color/two-chip experiments to circumvent sequence-specific signal deviations (see "Materials and Methods"). To validate this protocol, three tumor cell lines, known to carry multiple characteristic chromosomal aberrations, were examined by chromosomal $\mathrm{CGH}$ and matrix$\mathrm{CGH}$. Altered chromosomal regions of the cell lines COLO320-HSR, HL60, and NGP detected by conventional and matrix-CGH are summarized in Table 2 and Figure 3, respectively.

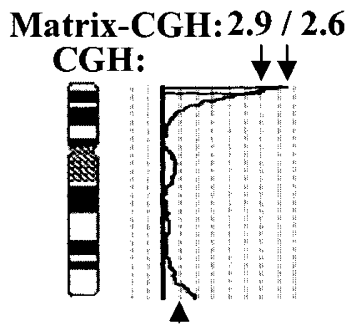

1.25

HDLM-2

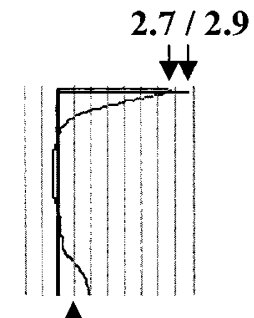

1.25

PMBL-16

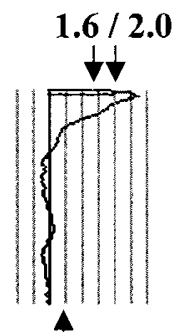

1.25

LMS-2

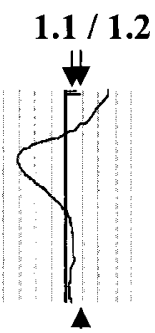

1.25

Figure 2.

Detection of amplification of the JAK2 gene in tumor cell populations, from which only small amounts of genomic DNA (PMBL-16, LMS-2, cHL-10) could be obtained and which was highly degraded in case of the leiomyosarcoma (LMS). Genomic DNA from these tumors required amplification by universal DOP-PCR. Genomic DNA of the tumor cell line HDLM-2 served as control. As shown by the ratio profiles along the chromosome 9 ideogram, chromosomal CGH detected a copy number increase (ie, signal ratios > 1.25) on 9p24 in all cases. Signal ratios measured after matrix-CGH with the same DNA on the two JAK2-specific PAC clones (clones $64,65)$ are indicated above the CGH ideograms. All JAK2-specific ratios were significantly higher than the ratios from the control clones, which were selected based on chromosomal CGH data ( $p<0.05$; Student $t$ test). Thus, the JAK2 gene is coamplified in these tumors, with low copy number gain in case of $\mathrm{CHL}-10$. 
Detection of High-Level Amplifications in Cell Lines COLO320 HSR, HL60, and NGP. For the diagnosis of high-level amplifications, a cut-off value of $2\left(=\log _{2} 1\right)$ was used for all matrix-CGH evaluations. In NGP, using chromosomal CGH, such amplifications were identified on the short arm of chromosome 2 (bands 2p23-p25) and on the long arm of chromosome 12 (bands 12q13-q15). With matrix-CGH, the described amplicon on chromosome 2 was indicated by a set of four clones, all of which covered the MYCN gene at 2p24.1 (clones 8, 9, 10, 11). The matrix-CGH ratios of 21.6 to 34.8 are representative for the actual genecopy numbers determined by Southern blot and FISH (Alitalo et al, 1983), whereas chromosomal CGH revealed ratios less than 5 . Similarly, on chromosome band $12 \mathrm{q} 13-\mathrm{q} 15$ the maximum matrix-CGH ratio was 5.5 (clone 102), exceeding the value of 1.75 by conventional CGH by more than 3-fold. Increased dynamic ranges of signal ratios were observed for all amplicons of our chip experiments, underlining the usefulness of microarray-based hybridization experiments.

Whereas chromosomal CGH indicated amplification of chromosomal band 12q12-q15, in matrix-CGH, two fragments from band 12q13 were scored to be balanced (clones 95, 96). Thus, the higher resolution of the method allowed fine mapping of the amplicon to genomic subsegments. Colon carcinoma cell line COLO320-HSR and promyelocytic leukemia cell line HL60 both carry high copy number amplifications of the MYC oncogene region on 8q24 (16-24 copies and 16-32 copies, respectively; Joos et al, 1993). As shown in Figure 4, for detailed array analysis we tested a contig of 8 clones spanning region 8q24 and the MYC oncogene (clones 55-62). Whereas in COLO320-HSR all clones of the contig consistently indicated gain, an amplification pattern with interspersed nonamplified gaps occurred in HL60. This characterization of subtle differences in the architecture of a common amplicon was verified and confirmed by FISH analysis using clones $55,56,58$, and 61 (data not shown).

Detection of Low Copy Number Changes. Low copy number gains display signal ratios of more than 1.25 (= $\log _{2} 0.32$ ), whereas losses result in signal ratios less than $0.75\left(=\log _{2}-0.41\right)$. In cell line HL60, a total of seven clones with ratios between 1.3 and 1.5 revealed gains on 1 p22 (clones 2, 3), 9p21-p24 (clones 63 65, 69, 70), and $15 \mathrm{q} 25$ (clones 117, 118) that were concordant with findings of chromosomal CGH. Typical losses of the interstitial region of chromosome 5 and the short arm of chromosome 17 were detected by clones mapping to $5 q 21,5 q 23$ (clones 34, 35), and 17p (clone 120), covering the TP53 tumor suppressor gene.

In COLO320-HSR and NGP, loss of chromosomal material on the long arm of chromosome 18 was identified with both standard and matrix-CGH. This was reflected by four of seven BAC targets mapping to chromosome 18 with signal ratios ranging from 0.6 to 0.7 (clones 126, 128-131). In NGP additional loss of chromosomal material on the long arm of chromosome 11 was identified by two targets mapping to $11 \mathrm{q} 23$, which both contain coding information of proto-oncogene ETS1 (clones 87, 88). The overall agreement between results of matrix-CGH and chromosomal CGH was $87 \%$ in HL60, $87 \%$ in NGP, and $81 \%$ in COLO320-HSR (see Table 1).

Analysis of Primary Tumor Cells. Based on the results from cell line evaluations, we reexamined DNA from the primary mediastinal B-cell lymphoma case reported above (PMBL16) using the 188 BAC/PAC chip. For the analysis of most primary tumors, no prior knowledge of chromosomal alterations is available, and thus control targets for normalization cannot be selected. For this reason, we used median-based automated normalization to assess the value of array CGH analysis as a primary diagnostic tool. In this experiment, the reported high-level amplification of the JAK2 gene was detected again by two PAC targets (clones 64,65) with ratios of 7.0 and 4.1. Low copy number gains on 2q35 (clone 19), 9p (clones 63, 66), 11q23 (clone 88), and losses at 4q25 (clone 32) and 22q12 (clone 151) were identified. All these imbalances were also scored by chromosomal CGH of this case (Joos et al, 1996). Interestingly, three clones mapping to Xp22 (clone 153-155) indicated a distinct gain that remained undetected by chromosomal CGH.

\section{Discussion}

Recently, the concept of CGH to arrayed DNA fragments for the detection of chromosomal aberrations has been introduced (Heiskanen et al, 2000; Pinkel et al, 1998; Pollack et al, 1999; Solinas-Toldo et al, 1997). We here present an elaborated protocol for matrix$\mathrm{CGH}$, which allows the fully automated analysis of genomic imbalances at a high resolution. Although the identification of genomic gains and losses corresponded well with the results obtained by chromosomal CGH, the dynamic range of the signal ratios was up to 5 times higher for matrix-CGH, allowing better quantitative assessments of a given imbalance. The potential of matrix-CGH to assign ratio amplitudes to selected genes or markers constitutes a particular advantage of this approach. This potential is used for high-resolution mapping of gains and losses on arrays of genomic contigs (Albertson et al, 2000; Bruder et al, 2001; Solinas-Toldo et al, 1997). In the present study, detailed analysis of the MYC amplicon on 8q24 in HL60 cells revealed a high heterogeneity of copy number increase along the genomic segment around the MYC gene. These data agree with a previous analysis of this amplicon by Southern blot hybridization (Joos et al, 1992). The observation of such heterogeneities is also in line with data obtained for other amplicons in tumor cell genomes by various means (Albertson et al, 2000; Reifenberger et al, 1996; Tanner et al, 1996). It can be expected that further highresolution analyses of amplified regions by matrixCGH will uncover numerous previously unrecognized heterogeneities within amplicons and will contribute to a refined modeling of the molecular mechanisms of DNA amplification in tumor cells.

In addition to its superior resolution, the potential of automation constitutes a particular advantage of 
A

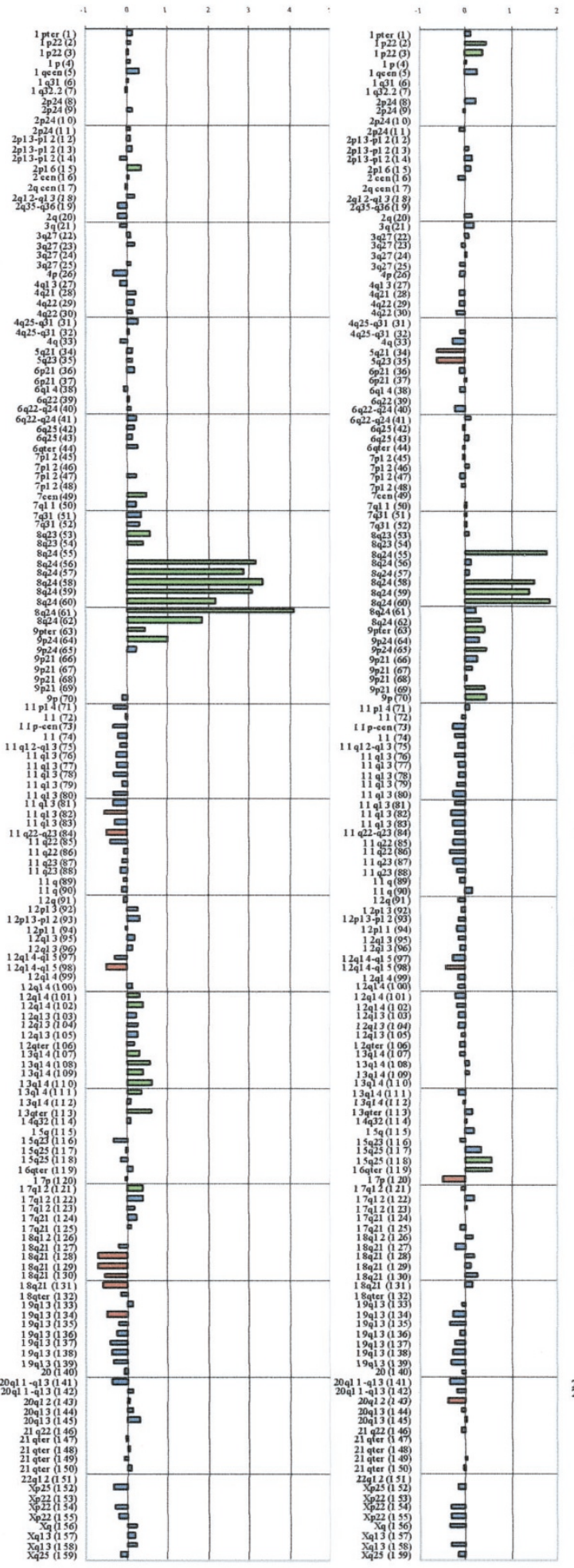

C

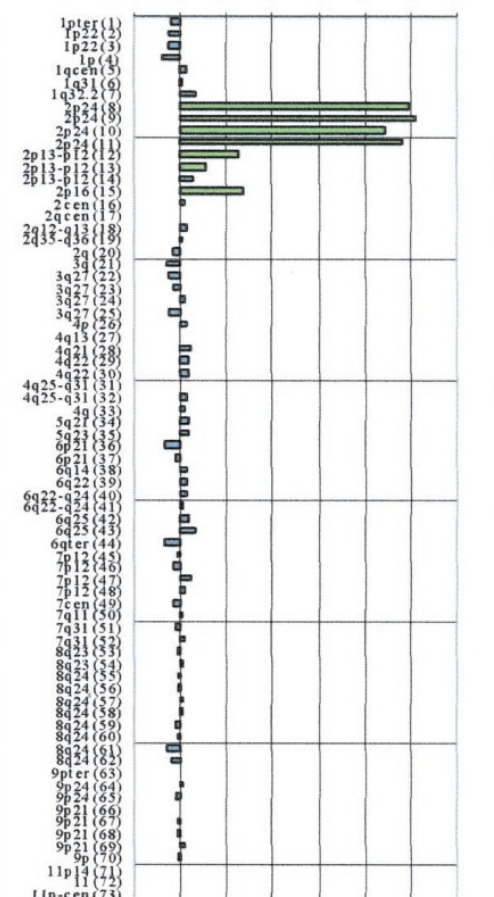

119

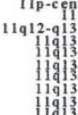

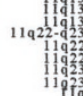

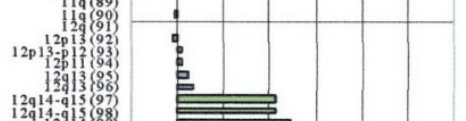

1294.948

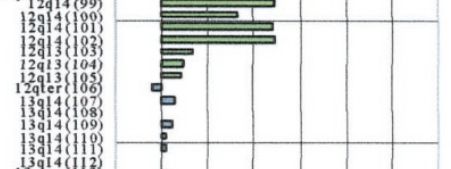

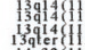
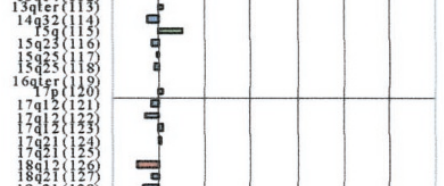

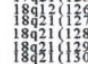

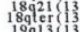

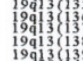

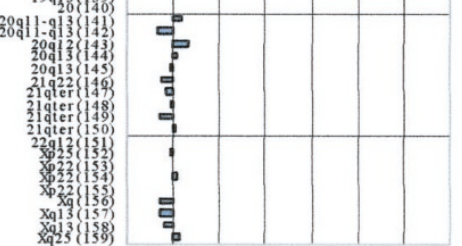

D

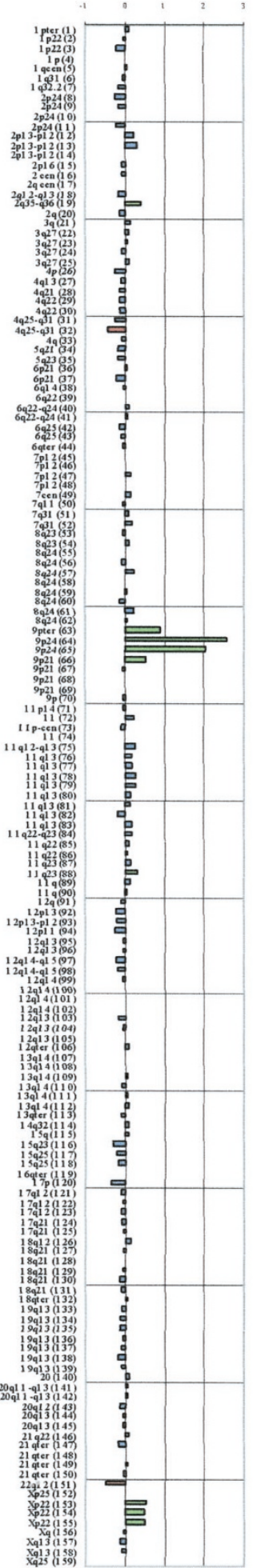

Figure 3.

Presentation of all matrix-CGH ratio values measured for the three tumor cell lines (A) COLO320-HSR, (B) HL60, (C) NGP and the primary mediastinal B-cell lymphoma (D). Gains are depicted in green, losses in red, and balanced regions in blue. Cut-off levels were 1.25 for gains and 0.75 for losses. Note that ratio values are presented as $\log _{2}$ values. For detailed signal ratios of targets indicating chromosomal imbalances also see Table 2. 

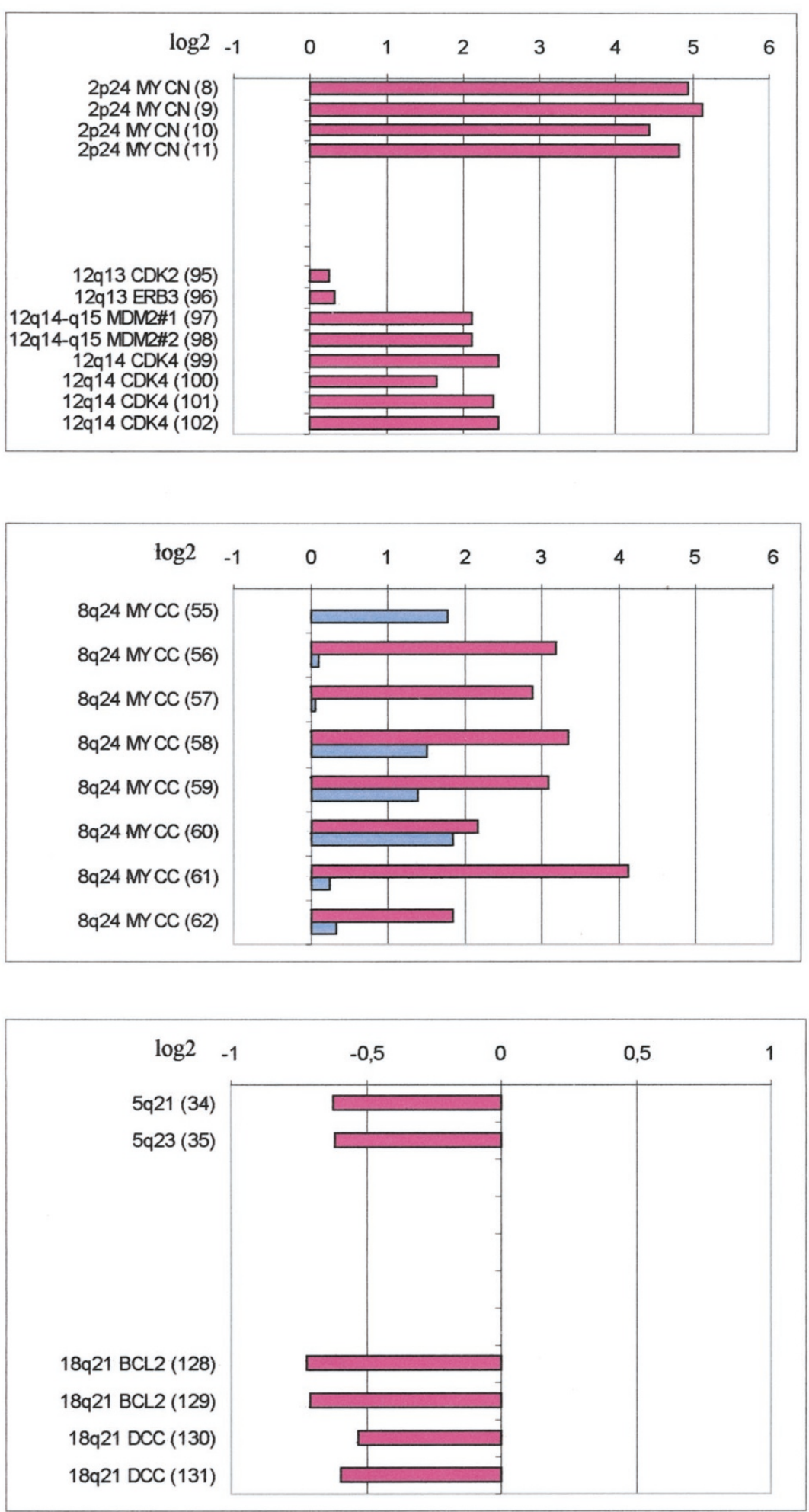

2p NGP

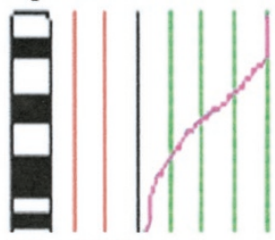

12q NGP

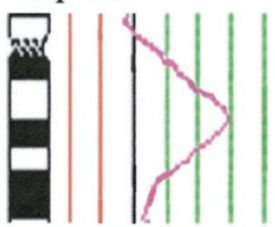

8q COLO320-HSR (red); HL60 (blue)

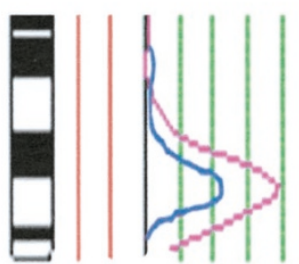

5q HL60

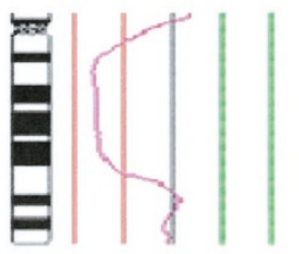

18q COLO320-HSR

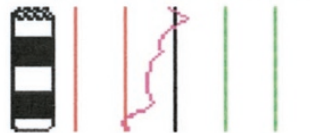

\section{Figure 4.}

Comparison of matrix-CGH and chromosomal CGH values. Examples are shown for tumor cell lines NGP (gains on 2p24 and 12q13-q15, red bars), COL0320-HSR (gains on $8 \mathrm{q} 24$ and loss on 18q21, red bars) and HL60 (gains on 8q24, blue bars, and loss on 5q21-q23, red bars). Although the scoring of the ratio values of the two methods is highly concordant, the absolute ratio values of the amplified regions are distributed over a much higher range for array signals, indicating the superior dynamics of matrix-CGH. 
Table 1. Total Numbers and Percentages of Concordant/Discordant Results in a Comparison of Chromosomal CGH Results with Matrix-CGH Experiments

\begin{tabular}{|c|c|c|c|c|}
\hline & NGP & HL60 & COL0320 & PMBL16 \\
\hline $\begin{array}{l}\text { Aberrations in } \\
\text { chromosomal } \mathrm{CGH}\end{array}$ & $\begin{array}{l}\text { enh1q, amp2p24, } \\
\text { enh8qter, dim10pter, } \\
\text { dim11qter, } \\
\text { amp12q13, enh17q, } \\
\text { dim18qter }\end{array}$ & $\begin{array}{l}\text { dim5qint, amp8q24, } \\
\text { enh9p, enh9qint, } \\
\text { enh13qter, dim14qint, } \\
\text { enh15qter, dim17p, } \\
\text { enh18 }\end{array}$ & $\begin{array}{l}\text { enh1cen, enh2p, } \\
\text { amp 8q24, } \\
\text { enh11p, enh 12p, } \\
\text { enh13q, dim18q, } \\
\text { dim19 }\end{array}$ & $\begin{array}{l}\text { enh2pter, dim3p, } \\
\text { dim4qint, enh5p, } \\
\operatorname{dim} 8 p, \text { amp9p24, } \\
\text { dim10q, enh11q, } \\
\text { enh16q, dim17p, } \\
\text { dim22q }\end{array}$ \\
\hline $\begin{array}{l}\text { Matrix-CGH total } \\
\text { evaluated targets }\end{array}$ & 148 & 151 & 148 & 153 \\
\hline $\begin{array}{l}\mathrm{mCGH} / \mathrm{CGH} \\
\text { concordance } \\
\text { total/percentage }\end{array}$ & $128 / 87$ & $131 / 87$ & $120 / 81$ & $129 / 85$ \\
\hline $\begin{array}{l}\text { Imbalanced in mCGH } \\
\text { balanced in } \mathrm{CGH} \\
\text { total/percentage }\end{array}$ & $3 / 2$ & $3 / 2$ & $8 / 5$ & $3 / 2$ \\
\hline $\begin{array}{l}\text { Balanced in mCGH } \\
\text { imbalanced in } \mathrm{CGH} \\
\text { total/percentage }\end{array}$ & $17 / 11$ & $17 / 11$ & $20 / 14$ & $21 / 14$ \\
\hline
\end{tabular}

CGH, comparative genomic hybridization.

matrix-CGH over chromosomal $\mathrm{CGH}$. To reach a high degree of automation, we developed and tested various devices for arraying of DNA fragments, hybridization, and scanning of the chips, which all required further adjustments and modifications of the original protocol. The procedure that emerged from these studies is detailed in "Materials and Methods." After extensive testing of protocol variants using the tumor cell lines HL60, COLO320-HSR, and NGP (not shown), the following steps are considered crucial for the performance of this technique.

Efficient labeling of probe and test DNA is an essential step of the procedure. A high labeling efficiency is accomplished by using linker-adapter PCR, as detailed in "Materials and Methods." Although this protocol was originally developed by Klein and co-

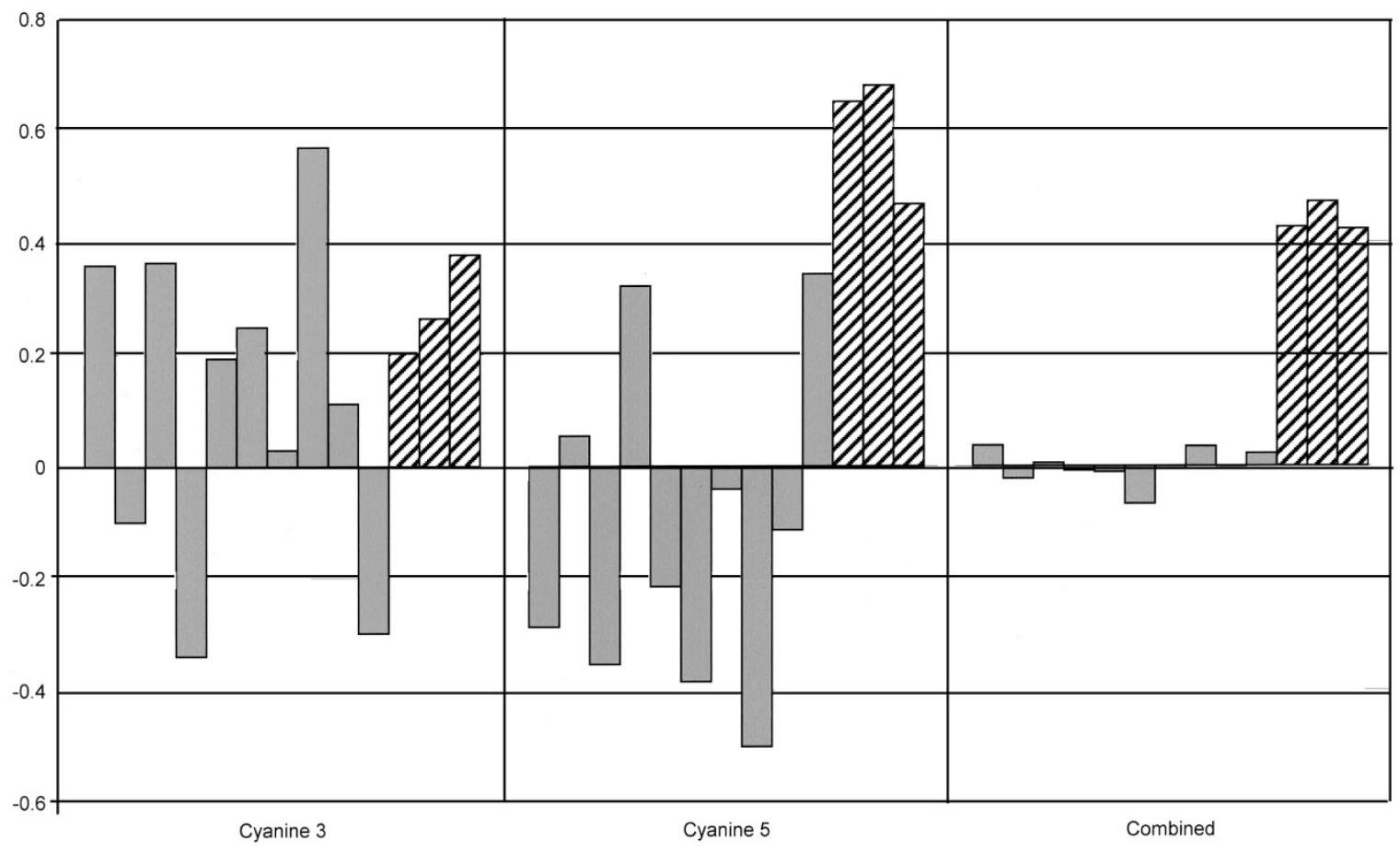

Figure 5.

Improved assessment of DNA copy number by applying color switch experiments. Some DNA fragments resulted in deviations from expected ratio values, when test DNA is labeled via Cy3 (left panel). For these fragments, reverse ratio values are obtained when the test DNA is labeled in Cy5 (middle panel). Averaging of the data of both experiments (right panel) yields the correct ratio values. In the diagram, gray boxes are representing balanced autosomal loci, whereas the hatched boxes indicate low copy gain of chromosome $X$ (hybridization of normal human female DNA versus normal human male DNA). 
Table 2. Synopsis of Target Names, Chromosomal Mapping Localizations, Normalized Logarithmic, and Numeric Signal Ratios for the Three Analyzed Cell Lines and PMBL 16

\begin{tabular}{|c|c|c|c|c|c|c|c|c|c|}
\hline Clone No. & Name & Locus & $\begin{array}{c}\log _{2} \\
\text { Ratios }\end{array}$ & $\begin{array}{l}\text { Num. } \\
\text { Ratios }\end{array}$ & Clone No. & Name & Locus & $\begin{array}{c}\log _{2} \\
\text { Ratios }\end{array}$ & $\begin{array}{l}\text { Num. } \\
\text { Ratios }\end{array}$ \\
\hline COLO 320 & Gain & & & & NGP & Gain & & & \\
\hline 5 & Alu6 & 1qcen & 0.34 & 1.3 & 7 & RPCIB753-P21193 & $1 \mathrm{q} 32$ & 0.33 & 1.3 \\
\hline 15 & RCPIP704-C2027 & $2 \mathrm{p} 16$ & 0.36 & 1.3 & 9 & RPCIP704-D1362 & $2 \mathrm{p} 24$ & 5.12 & 34.8 \\
\hline 51 & $1024 \mathrm{H} 20$ & $7 \mathrm{q} 31$ & 0.37 & 1.3 & 8 & RPCIP-704-B031128 & & 4.95 & 30.9 \\
\hline 49 & RPCIB753-G03211 & $7 \mathrm{cen}$ & 0.48 & 1.4 & 11 & RPCIP704-J181107 & & 4.80 & 27.9 \\
\hline 53 & RPCIP704-J01305 & $8 q 23$ & 0.57 & 1.5 & 10 & RPCIP704-H031101 & & 4.43 & 21.6 \\
\hline 54 & RPCIP704-L0411 & & 0.4 & 1.3 & 15 & RCPIP704-C2027 & $2 \mathrm{p} 16$ & 1.35 & 2.5 \\
\hline 56 & RPCIP704-F15291 & $8 q 24$ & 3.19 & 9.1 & 12 & RPCIB753-E1991 & $2 p 13-p 12$ & 1.27 & 2.4 \\
\hline 57 & RPCIP704-C07126 & & 2.87 & 7.3 & 13 & RPCIB753-G1991 & & 0.56 & 1.5 \\
\hline 58 & RPCIP704-K19268 & & 3.35 & 10.2 & 97 & MDM2\#1 & $12 q 14-q 15$ & 2.12 & 4.3 \\
\hline 59 & RPCIP704-K2280 & & 3.08 & 8.5 & 98 & MDM2\#2 & & 2.12 & 4.3 \\
\hline 60 & RPCIP704-J08127 & & 2.17 & 4.5 & 103 & GLI\#1 & $12 q 13$ & 0.64 & 1.6 \\
\hline 61 & RPCIB704-M14318 & & 4.12 & 17.4 & 104 & GLI\#2 & & 0.46 & 1.4 \\
\hline 62 & RPCIP704-K22117 & & 1.84 & 3.6 & 105 & GLI\#3 & & 0.4 & 1.3 \\
\hline 63 & RPCIP-I18310 & 9pter & 0.45 & 1.4 & 99 & RPCIP704-J15872 & $12 \mathrm{q} 14$ & 2.46 & 5.5 \\
\hline 64 & PJ2A & $9 \mathrm{p} 24$ & 0.98 & 2.0 & 100 & RPCIP704-J13765 & & 1.65 & 3.1 \\
\hline 101 & RPCIP704-L16872 & $12 q 13$ & 0.33 & 1.3 & 101 & RPCIP704-L16872 & & 2.40 & 5.3 \\
\hline 102 & RPCIP704-P08773 & & 0.39 & 1.3 & 102 & RPCIP704-P08773 & & 2.47 & 5.5 \\
\hline 107 & RPCIP704-A12173 & $13 q 14$ & 0.33 & 1.3 & 115 & RPCIB753-J2397 & $15 q$ & 0.518 & 1.4 \\
\hline 108 & RPCIP704-018295 & & 0.55 & 1.5 & & & & & \\
\hline 109 & RPCIP704-D01197 & & 0.42 & 1.3 & & & & & \\
\hline 110 & RPCIB753-I10174 & & 0.61 & 1.5 & & & & & \\
\hline 111 & RPCIP704-J10250 & & 0.38 & 1.3 & & & & & \\
\hline 113 & RPCIP704-C13249 & 13ate & 0.60 & 1.5 & & & & & \\
\hline 121 & RPCIB753-D0581 & $r$ & 0.41 & 1.3 & & & & & \\
\hline \multirow[t]{2}{*}{122} & RPCIB753-K1579 & $17 q 12$ & 0.41 & 1.3 & & & & & \\
\hline & Loss & & & & & Loss & & & \\
\hline 82 & 778P1 & $11 \mathrm{q} 13$ & -0.54 & 0.7 & 87 & RPCIB753-E09209 & $11 \mathrm{q} 23$ & -0.43 & 0.7 \\
\hline 84 & PAC755B11 & $11 \mathrm{q} 22$ & -0.5 & 0.7 & 88 & RPCIB753-C04223 & & -0.74 & 0.6 \\
\hline 98 & MDM2\#2 & $12 q 13$ & -0.48 & 0.7 & 126 & RPCIB753-N16242 & $18 q 12$ & -0.49 & 0.7 \\
\hline 128 & RPCIB753-B19566 & $18 \mathrm{~g} 21$ & -0.72 & 0.6 & 130 & RPCIB753-001869 & $18 \mathrm{q} 21$ & -0.58 & 0.7 \\
\hline 129 & RPCIB753-C20566 & & -0.71 & 0.6 & 132 & RPCIP704-A17171 & 18ater & -0.83 & 0.6 \\
\hline 130 & RPCIB753-001869 & & -0.53 & 0.7 & 137 & RPCIB753-I1679 & $19 q 13$ & -0.57 & 0.7 \\
\hline 131 & RPCIB753-P21751 & & -0.6 & 0.7 & 138 & RPCIB753-J1735 & & -0.49 & 0.7 \\
\hline 134 & RPCIP704-M02787 & $19 q 13$ & -0.48 & 0.7 & & & & & \\
\hline PMBL16 & Gain & & & & HL60 & Gain & & & \\
\hline 19 & RPCIB753-E23247 & $2 q 35$ & 0.40 & 1.3 & 2 & RPCIB753-E16254 & $1 \mathrm{p} 22$ & 0.44 & 1.4 \\
\hline 66 & RPCIB753-C0689 & $9 \mathrm{p} 21$ & 0.53 & 1.4 & 3 & RPCIB753-004246 & & 0.35 & 1.3 \\
\hline 64 & PJ2A & $9 \mathrm{p} 24$ & 2.58 & 5.7 & 55 & RPCIP704-H027 & $8 q 24$ & 1.77 & 3.4 \\
\hline 65 & PJ2B & & 2.0 & 3.7 & 58 & RPCIP704-K19268 & & 1.51 & 2.8 \\
\hline 63 & RPCIP704-I18310 & 9pter & 0.87 & 1.8 & 59 & RPCIP704-K2280 & & 1.38 & 2.6 \\
\hline 88 & RPCIB753-C04223 & $11 \mathrm{q} 23$ & 0.32 & 1.3 & 60 & RPCIP704-J08127 & & 1.85 & 3.6 \\
\hline 153 & RPCIB753-L08543 & Хp22 & 0.52 & 1.4 & 62 & RPCIP704-K22117 & & 0.33 & 1.3 \\
\hline 155 & RPCIB753-N0680 & & 0.49 & 1.4 & 63 & RPCIP704-I18310 & 9pter & 0.41 & 1.3 \\
\hline \multirow[t]{7}{*}{154} & RPCIB753-F0990 & & 0.47 & 1.4 & 65 & $\begin{array}{l}\text { PJ2B } \\
\text { P }\end{array}$ & $9 \mathrm{p} 24$ & 0.42 & 1.3 \\
\hline & & & & & 69 & RPCIB753-E2179 & $9 p 21$ & 0.41 & 1.3 \\
\hline & & & & & 70 & RPCIB753-B18462 & $9 p$ & 0.46 & 1.4 \\
\hline & & & & & 117 & RPCIP704-M04155 & $15 q 25$ & 0.32 & 1.3 \\
\hline & & & & & 118 & RPCIP704-012217 & & 0.56 & 1.5 \\
\hline & & & & & 119 & RPCIP704-E15271 & $16 q$ ter & 0.57 & 1.5 \\
\hline & Loss & & & & & Loss & & & \\
\hline & RPCIP704-C12204 & $4 q 25$ & -0.44 & 0.7 & 34 & RPCIB753-J2037 & $5 q 21$ & -0.62 & 0.7 \\
\hline \multirow[t]{4}{*}{151} & RPCIB753-I15690 & $22 q 12$ & -0.49 & 0.7 & 35 & RPCIB753-M23265 & $5 q 23$ & -0.62 & 0.7 \\
\hline & & & & & 98 & MDM2\# & $12 q 13$ & -0.42 & 0.7 \\
\hline & & & & & 120 & P53 & $17 \mathrm{p}$ & -0.49 & 0.7 \\
\hline & & & & & 143 & RPCIB753-E18832 & $20 q 12$ & -0.41 & 0.7 \\
\hline
\end{tabular}

The clone number refers to the number in brackets listed in figures 3 and 4 . 
workers to facilitate universal amplification of genomic DNA samples (Klein et al, 1999), it proved to be highly potent also for the labeling of matrix-CGH probes.

The complexity of human genomic DNA is several orders of magnitude higher than CDNA pools derived from a given tissue. Thus, matrix-CGH is much more demanding, and hybridization conditions have to be optimized to increase the likelihood of the pairing of homologous sequences. One strategy to improve the hybridization efficiency is elevation of the hybridization temperature and simultaneous decrease of formamide (or increase of salt) concentration to adjust for the stringency of the reaction (Solinas-Toldo et al, 1997). Another strategy to increase the likelihood that a given sequence in solution meets its counterpart immobilized on the chip is the application of microfluidic devices, which agitate the hybridization cocktail, resulting in higher kinetics of the labeled molecules. Both strategies are combined in the protocol reported here, performing hybridization at $50^{\circ} \mathrm{C}$ (versus $37^{\circ} \mathrm{C}$ ) in an automated hybridization chamber. Active pumping of the solution over a chip not only fosters the hybridization event but also results in a considerable reduction of background signal.

Matrix-CGH is particularly sensitive to background noise because the range of the signal ratios for scoring genomic gains and losses requires an accuracy of less than 0.1 . In the course of elaborating our protocol, it became evident that each step of the procedure potentially adds to the background level. We therefore focused on minimizing the number of treatments of the slides. In particular, omission of the following steps before hybridization was found to be beneficial: (a) additional denaturation of the immobilized DNA fragments by heat or alkali treatment, (b) dehydration in alcohol, and (c) treatment of chips by blocking solutions.

For some genomic DNA fragments, deviations of the expected ratio values were repeatedly observed. Most of these false results could be corrected when the socalled color switch experiments were performed (see Fig. 5, "Materials and Methods"). Each experiment is carried out once with test and control probe labeled in Cy3 and Cy5 and once with the reverse labeling. After averaging both ratios, most initially outlying fragments yielded accurate scores presented by the average ratio. Therefore, we now routinely perform matrix-CGH including the color switch experiment. Because the false data, obtained by one color combination, could not be overcome by repetition of the labeling and hybridization, this phenomenon is best explained by a differential interaction of the Cy3 and Cy5 dyes with certain classes of DNA sequences, such as GC-rich or -poor segments of the DNA.

Normalization factors for the evaluation of all cell line experiments were determined through the mean values of a set of clones mapping across the genome, which were preselected from regions not known to be affected in hematological neoplasias. Because of the limited amount of targets, this procedure ensured the most precise normalization factors. Less consistent results were obtained by alternative algorithms for normalization based on mean or median ratio values of all targets of a given array. Here, asymmetric signal distributions, together with a restricted number of control targets, resulted in imprecise normalization. Control clones were selected from regions that were balanced according to chromosomal CGH profiles. Further refinement of the normalization procedure was accomplished by an in-

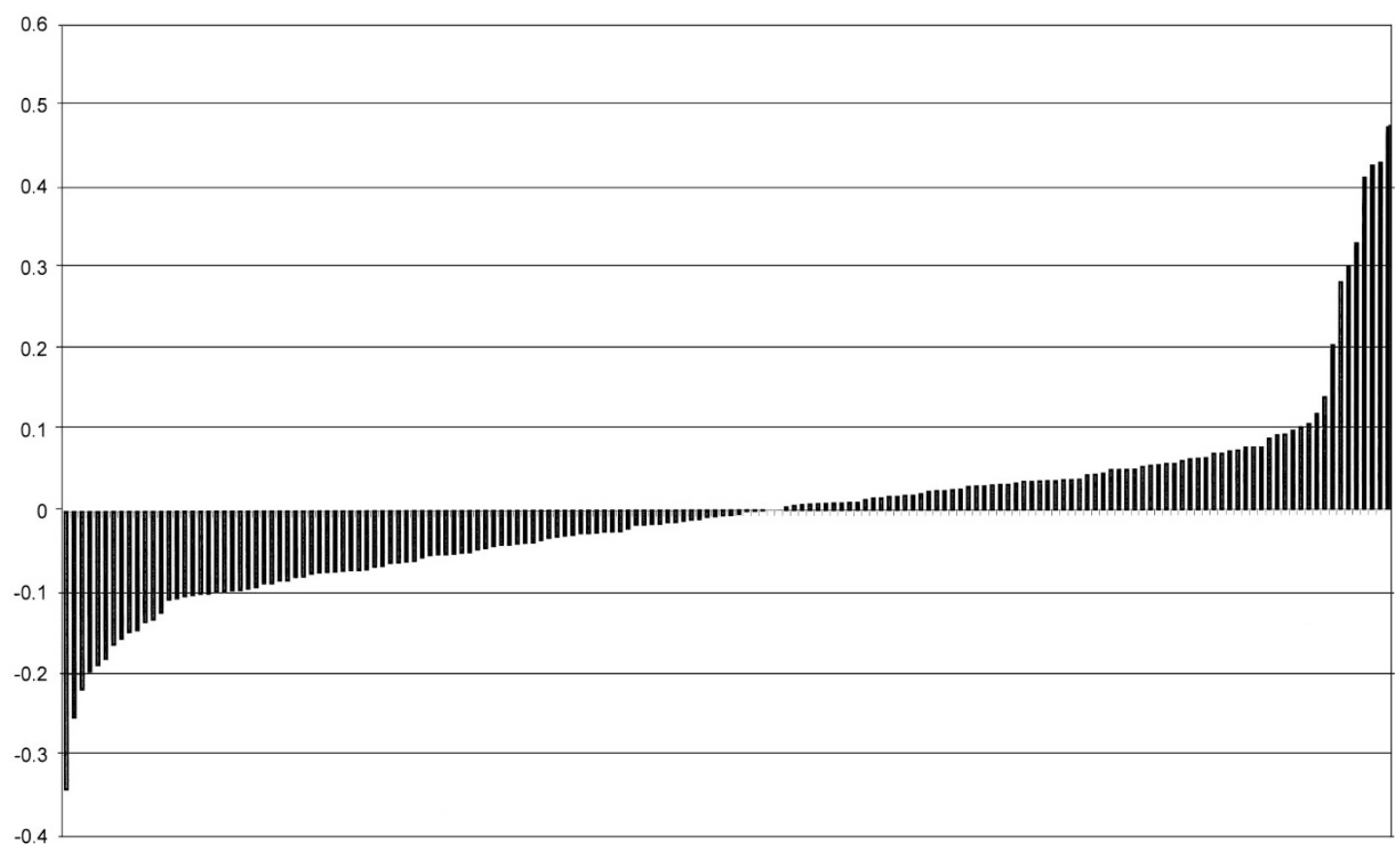

Figure 6.

Histogram showing the ratio values (as $\log _{2}$ values) of a matrix-CGH experiment comparing DNA from normal human male versus normal human female cells in ascending order (for detail see text). 
crease in the number of control clones, allowing normalization based on independent algorithms. This principle has been shown in the PMBL case, where medianbased normalization has proven to be accurate. However detection of imbalances in nondiploid cells or cells that are known to carry multiple aberrations (eg, affecting more than one third of the genome) can be particularly challenging. Accordingly, median-based normalization relying on few controls with tumors harboring a high percentage of chromosomal aberrations resulted in imprecise ratios due to minimal shifts of the underlying normalization factor (not shown). This problem is overcome when using large numbers of control clones more or less evenly distributed across the entire genome at high density. Taking this into account, chip-based detection and high-resolution mapping of unknown imbalances is feasible for any tumor cell population.

The data of the present study demonstrate that matrix-CGH discloses the specific copy number changes with a much higher degree of accuracy. Thus, it can be expected that multiple small imbalances, which were so far overlooked, will be detected when applying this new approach. A number of applications of array-based CGH can be envisioned in the field of tumor genetics (Lichter et al, 2000), of which many will benefit from the potential to analyze small samples enriched by microdissection or cell sorting. As well as screening for imbalances affecting known tumor suppressor or oncogenes, high-density arrays covering the whole genome can be used to screen for yet unknown regions harboring genes of pathogenic relevance. Disease-specific chips could widen the spectrum of diagnostic tools and contribute to clinical risk stratified tumor therapies. Triggered first by karyotyping, this approach has successfully enriched modern regimens for therapies in malignant diseases (Döhner et al, 1999, 2000). Genomic profiling by matrixCGH may provide a basis for an integrated approach for the molecular characterization of malignant diseases, including expression profiling on the level of RNA and protein (Alizadeh et al, 2000; DeRisi et al, 1996, 1997; Diehn et al, 2000; Golub et al, 1999; Lipshutz et al, 1999; Schena et al, 1996; Stratowa et al, 2001). Automation of the protocol as presented in this study is mandatory for such widespread applications.

\section{Materials and Methods}

\section{Target Clones Representing Distinct Genes or Regions of Interest}

Target DNAs were isolated from 188 clones containing inserts approximately 90 to $230 \mathrm{~kb}$ in length from human BAC library RPCIB753 or PAC library RPCIP704 (German Resource Center, Berlin, Germany). To allow gene or marker-directed analysis, clones were selected based on their chromosomal localization or their gene content. cDNAs from candidate genes were isolated from a fetal heart library by PCR. Subsequently, these cDNAs were used for filter hybridizations yielding in the isolation of $\mathrm{BAC}$ and PAC clones, the identity of which was determined by FISHmapping and PCR. In addition, cDNA-sequences were obtained from database queries at the National Center for Biotechnology Information (http://www.ncbi.nlm. nih.gov/Entrez/) and used for BLAST-search (http:// www.ncbi.nlm.nih.gov/BLAST/) against unfinished high throughput genomic sequenced clones to identify further targets. Clones covering specific chromosomal regions were selected using the physical chromosome maps of Entrez Genome (http://www.ncbi. nlm.nih.gov:80/cgi-bin/Entrez/maps.cgi?org=hum \& $\mathrm{chr}=1$ ). FISH mapping was performed in all cases to ensure correct chromosomal mapping. DNA preparations were prepared from $400 \mathrm{ml}$ LB-cultures using standard preparation kits (QIAGEN, Hilden, Germany). For higher yield, 2- to 3-fold buffer volumes were used for resuspension, lysis, neutralization, and final elution. After resolving DNA in $500 \mu \mathrm{ldH_{2 }}$ O and photometric concentration measurement, a 30 -second sonification step reduced sample viscosity and sized fragments to several hundred nucleotides. After standard ethanol precipitation, the final target concentration was adjusted to approximately 0.5 to $1 \mu \mathrm{g} / \mu \mathrm{l}$. Occasionally, selected BACs resulted in incoherent ratio values for reasons not well understood and therefore were omitted. The origins, names, and ID numbers of the DNA fragments are listed at http://www.dkfz-heidelberg. de/kompl_genome/index.html.

\section{Arraying and Immobilization of BAC and PAC Targets on Solid Glass Supports}

Targets were picked from 384-well PCR microtiter plates with 16 SMP3 split pins (TeleChem International, Sunnyvale, California) using the omnigrid multiaxis robotic microarrayer (GeneMachines, San Carlos, California) and spotted on poly-L-lysin-coated slides (Sigma-Aldrich, Munich, Germany). For each sample 10 spots were printed with an average diameter of 150 to $200 \mu \mathrm{m}$. Best spotting results were achieved with $0.5 \mu \mathrm{g} / \mu \mathrm{l}$ DNA in $3 \times$ SSC. Target DNA sonification, resulting in fragments several hundred nucleotides in length before spotting, helped to reduce occlusion of the split pins while printing. Moreover, spot morphology appeared more homogeneous than with nonsonified DNA, resulting in lower standard deviations of the replicas. Immediately after arraying, the slides were baked at $80^{\circ} \mathrm{C}$ for 10 minutes and DNA was crosslinked by UV light of 254 $\mathrm{nm}$, applying $240 \mathrm{~mJ}$ (UV-Stratalinker; Stratagene, Amsterdam, Netherlands). All slides were stored in boxes with drying agent at room temperature.

Target immobilization and spot morphology were influenced strongly by the different slide surfaces that were applied. In our hands poly-L-lysine-coated slides (Sigma) achieved best results with regard to minimized spot size, consistent spot morphology, and absence of target confluence. However it was mandatory to preselect only those slides with clean and homogeneous surfaces to avoid loss of target DNA and high background. Various pretreatment procedures before and after spotting were tested but in our hands did not 
improve signal to background ratios significantly and were therefore disregarded. It was not necessary to perform an additional step for denaturation of the target DNA. The application of a prewarmed hybridization chamber (Genomic Solutions, San Diego, California) with constant agitation of the hybridization solution proved to be beneficial for background reduction and low intrachip variability.

\section{Preparation of Test and Control DNA}

Whole genomic DNA was prepared using a standard phenol chloroform extraction protocol from the following sources: colon carcinoma cell line COLO320-HSR (Quinn et al, 1979), promyelocytic leukemia cell line HL60 (Dalla-Favera et al, 1982), neuroblastoma cell line NGP (Schwab et al, 1984), Hodgkin's lymphoma cell line HDLM-2 (Drexler et al, 1986), Hodgkin's lymphoma CHL-10 (Joos et al, 2000), a primary mediastinal B-cell lymphoma (PMBL-16; Joos et al, 1996), a leiomyosarcoma (LMS-2; Otano-Joos et al, 2000), and peripheral blood lymphocytes of a healthy human donor. All primary tumors were known to carry an amplification of the 9p24 region including a coamplification of the JAK2 gene. CGH to metaphase chromosome spreads was performed according to standard protocols (Lichter et al, 1995 and references therein).

A number of different labeling techniques were tested: (a) standard nick translation (Langer et al, 1981), (b) standard DOP-PCR (Kuukasjarvi et al, 1997; Telenius et al, 1992), (c) cisplatinum-fluorochrome coupling (KREATECH, Amsterdam, Netherlands), and (d) linker-adapter-PCR (Klein et al, 1999). Cisplatinumfluorochrome compounds resulted in high signal intensities but yielded an unsatisfactory reproducibility of signal ratios. A previously published PCR strategy for global amplification and labeling of genomic DNA (Klein et al, 1999) proved to be particularly useful. Briefly, $0.5 \mu \mathrm{g}$ DNA was digested by Msel restriction endonuclease for 3 hours at $37^{\circ} \mathrm{C}$. After adding a 12-mer (5'-TAA CTA GCA TGC-3') and a 21-mer (5'-AGT GGG ATT CCG CAT GCT AGT-3') primer, annealing was allowed during continuous temperature shifting from $65^{\circ} \mathrm{C}$ down to $15^{\circ} \mathrm{C}$ at $1^{\circ} \mathrm{C} /$ minute in a GeneAmp 9700 Thermocycler (PE Applied Biosystems, Foster City, California). Ligation of primer and restriction fragments in the presence of T4-DNA ligase and ATP was allowed overnight. A short fill-in reaction was followed by primary amplification in $40-\mu \mathrm{l}$ reaction volume and 38 temperature cycles using a mixture of Taq and Pwo polymerase (Roche, Basel, Switzerland). Of the reaction product, $0.5 \mu \mathrm{l}$ was directly subjected to a second PCR/labeling reaction for 25 cycles using Thermo Sequenase (Amersham Pharmacia Biotech, Freiburg, Germany). Differing from the original protocol, we used a dNTP mixture substituting biotin/digoxigenin-labeled nucleotides by cyanine 3or cyanine 5-coupled dCTP (PerkinElmer Life Science Products, Boston, Massachusetts) with a 1/7 CyXdCTP/dCTP ratio for optimized labeling. Unincorporated nucleotides and primers were removed by Sephadex $\mathrm{G} 50$ spin columns.

\section{Hybridization}

The hybridization cocktail contained $1 \mu \mathrm{g}$ of differentially labeled control and tumor DNA coprecipitated with $60 \mu \mathrm{g}$ of human Cot-1 DNA and resolved in 120 $\mu \mathrm{l}$ prewarmed ULTRAhyb buffer (Ambion, Austin, Texas) at $37^{\circ} \mathrm{C}$ for $>30$ minutes. After denaturation at $75^{\circ} \mathrm{C}$ for 5 minutes, preannealing of repetitive DNA sequences was allowed for 60 minutes at $37^{\circ} \mathrm{C}$. All slides were mounted into a GeneTac (Genomic Solutions) automated hybridization chamber. Before the application of the probes, slides were heated to $50^{\circ} \mathrm{C}$ for 10 minutes. Hybridization was allowed for 36 hours at $52^{\circ} \mathrm{C}$. Slides were washed three times for 5 minutes in $50 \%$ formamide and $2 \times \mathrm{SSC}, \mathrm{pH} 7.0$, at $42^{\circ} \mathrm{C}$. Additional washing in $0.01 \%$ SSC at $42^{\circ} \mathrm{C}$ followed three times for 5 minutes. Slides were dehydrated in a series of $70 \%, 90 \%$, and $100 \%$ ethanol.

\section{Combination of Two-Color/Two-Chip Experiments}

Initial chip experiments revealed unexpected ratio alterations for certain target clones ranging from $\log _{2}$ -0.6 to $\log _{2}+0.6$. This phenomenon is likely due to sequence-specific affinities of the fluorescent dyes. Therefore, we performed color switch experiments in which test and control DNA were labeled via Cy3 and Cy5, respectively, and vice versa. Averaging the twocolor/two-chip experiments resulted in precise ratios. A combined color switch experiment of human male versus human female DNA is illustrated in Figure 6. More than $95 \%$ of all clones were distributed between 1.14 and $0.87\left(=\log _{2} \pm 0.2\right)$ calculated with linear ratios. A total of eight clones from chromosome $X$ were detected as gain by use of this threshold, five were detected at $\log _{2}+0.32(=1.25)$ as cutoff. In Figure 5 data are depicted for a subset of targets demonstrating that averaging of the two color switch ratios resulted in a higher accuracy of final ratios.

\section{Imaging and Evaluation}

Images were acquired using a GenePix4000 A (Axon Instruments, Burlingame, California) dual laser scanner in combination with GenePixPro 3.0 imaging software. Two simultaneous scans of each array were obtained at wavelengths $635 \mathrm{~nm}$ and $532 \mathrm{~nm}$, respectively. After segmentation of hybridization signals, background and signal intensities were extracted from both images and exported as raw data to a dedicated analysis software tool, developed in-house, to allow quality control as well as statistical data analysis. Evaluation consisted of the following consecutive steps: Pixel intensities of each feature were integrated and median values were determined using the software GenePix Pro 3.0. Local background was calculated from the area surrounding each spot defined as follows: The radius of the spot circle was multiplied by three (3r) and from the area defined by the circle with this radius the spot circle area with the radius $r+3$ pixels was subtracted. The signal values were further processed using the MCGH software (developed by our group using Visual Basic 6.0). For each spot the 
intensities (pixel median values) were corrected for both wavelengths by subtracting the local background (pixel median values). On the basis of these corrected intensities, the $\log _{2}$ values for the signal ratios (Cy3/ Cy5) were calculated. The 10 replicate features of each target were filtered by minimum/maximum outlier reduction and by elimination of any spot that had been flagged by the analysis software or interactively because of misplacement or inferior spot morphology. From the remaining replicates, the mean value and its standard deviation were calculated. Target values with standard deviations greater than \pm 0.3 or signal/background ratios less than 2 were excluded from the analysis. Signal ratio values were considered only for those targets for which the results of both (color switch) experiments were accepted. The final ratio was obtained by averaging the results of the two corresponding experiments.

Control targets for normalization were preselected on the basis of unsuspicious chromosomal CGH ratio values for all cell line experiments. The cluster of controls for the primary tumor PMBL-16 was determined using the values for the $20 \%$ of the targets closest to the median value. In concordance with chromosomal CGH analysis procedures, the thresholds for low copy number gains and losses were set to $\log _{2} 0.32$ and $\log _{2}-0.41$, respectively, which correspond to the values of 1.25 and 0.75 , respectively, and high-level amplifications were scored for ratios higher than $\log _{2} 1=2.0$. Result files were Excel compatible to facilitate graphic representations.

\section{Acknowledgements}

We thank Manfred Schwab and Gunhild Mechtersheimer (both Heidelberg), Stephan Stilgenbauer, Peter Möller (both Ulm), Guido Reifenberger (Düsseldorf), Peter Marynen (Leuven), and Lorenz Trümper (Göttingen) for providing DNA probes and tumor samples, and Katrin Wildenberger, Sabina Solinas-Todo (both Heidelberg), Gabi Linder (Ulm), and Christoph Klein (München) for sharing technical knowledge.

\section{References}

Albertson DG, Ylstra B, Segraves R, Collins C, Dairke, SH, Kowbel D, Kuo WL, Gray JW, and Pinkel D (2000). Quantitative mapping of amplicon structure by array CGH identifies CYP24 as a candidate oncogene. Nat Genet 25:144-146.

Alitalo K, Schwab M, Lin CC, Varmus HE, and Bishop, JM (1983). Homogeneously staining chromosomal regions contain amplified copies of an abundantly expressed cellular oncogene (c-myc) in malignant neuroendocrine cells from a human colon carcinoma. Proc Natl Acad Sci USA 80:17071711.

Alizadeh AA, Eisen MB, Davis RE, Ma C, Lossos IS, Rosenwald A, Boldrick JC, Sabet H, Tran T, Yu X, Powell JI, Yang L, Marti GE, Moore T, Hudson J, Lu L, Lewis DB, Tibshirani R, Sherlock G, Chan WC, Greiner TC, Weisenburger DD, Armitage JO, Warnke R, and Staudt LM (2000). Distinct types of diffuse large B-cell lymphoma identified by gene expression profiling. Nature 403:503-511.
Bentz M, Barth TF, Brüderlein S, Bock D, Schwerer MJ, Baudis M, Joos S, Viardot A, Feller AC, Müller-Hermelink HK, Lichter P, Döhner H, and Möller P (2001). Gain of chromosome arm $9 p$ is characteristic of primary mediastinal B-cell lymphoma (MBL): Comprehensive molecular cytogenetic analysis and presentation of a novel MBL cell line. Genes Chromosomes Cancer 30:393-401

Bentz M, Plesch A, Stilgenbauer S, Döhner H, and Lichter P (1998). Minimal sizes of deletions detected by comparative genomic hybridization. Genes Chromosomes Cancer 21: 172-175.

Bruder CE, Hirvela C, Tapia-Paez I, Fransson I, Segraves R, Hamilton G, Zhang XX, Evans DG, Wallace AJ, Baser ME, Zucman-Rossi J, Hergersberg M, Boltshauser E, Papi L, Rouleau GA, Poptodorov G, Jordanova A, Rask-Andersen H, Kluwe L, Mautner V, Sainio M, Hung G, Mathiesen, T, Moller C, Pulst SM., Harder H, Heiberg A, Honda M, Niimura M, Sahlen S, Blennow E, Albertson DG, Pinkel D, and Dumanski JP (2001). High resolution deletion analysis of constitutional DNA from neurofibromatosis type 2 (NF2) patients using microarray-CGH. Hum Mol Genet 10:271-282.

Dalla-Favera R, Wong-Staal F, and Gallo RC (1982). Oncogene amplification in promyelocytic leukaemia cell line HL-60 and primary leukaemic cells of the same patient. Nature 299:61-63.

DeRisi J, Penland L, Brown PO, Bittner ML, Meltzer PS, Ray M, Chen Y, Su YA, and Trent JM (1996). Use of a cDNA microarray to analyse gene expression patterns in human cancer. Nat Genet 14:457-460.

DeRisi JL, lyer VR, and Brown PO (1997). Exploring the metabolic and genetic control of gene expression on a genomic scale. Science 278:680-686.

Diehn M, Eisen MB, Botstein D, and Brown PO (2000). Large-scale identification of secreted and membraneassociated gene products using DNA microarrays. Nat Genet 25:58-62.

Döhner H, Stilgenbauer S, Benner A, Leupolt E, Kröber A, Bullinger L, Döhner K, Bentz M, and Lichter P (2000). Genomic aberrations and survival in chronic lymphocytic leukemia. N Engl J Med 343:1910-1916.

Döhner H, Stilgenbauer S, Bentz M, and Lichter P (1999). Chromosome aberrations in B-cell chronic lymphocytic leukemia: Reassessment based on molecular cytogenetic analysis. J Mol Med 77:266-281.

Drexler HG, Gaedicke G, Lok MS, Diehl V, and Minowada J (1986). Hodgkin's disease derived cell lines HDLM-2 and L-428: Comparison of morphology, immunological and isoenzyme profiles. Leuk Res 10:487-500.

Du Manoir S, Speicher MR, Joos S, Schröck E, Popp S, Döhner H, Kovacs G, Robert-Nicoud M, Lichter P, and Cremer T (1993). Detection of complete and partial chromosome gains and losses by comparative genomic in situ hybridization. Hum Genet 90:590-610.

Forozan F, Karhu R, Kononen J, Kallioniemi A, and Kallioniemi OP (1997). Genome screening by comparative genomic hybridization. Trends Genet 13:405-409.

Golub TR, Slonim DK, Tamayo P, Huard C, Gaasenbeek M, Mesirov JP, Coller H, Loh ML, Downing JR, Caligiuri MA, Bloomfield CD, and Lander, ES (1999). Molecular classification of cancer: class discovery and class prediction by gene expression monitoring. Science 286:531-537. 
Heiskanen MA, Bittner ML, Chen Y, Khan J, Adler KE, Trent $\mathrm{JM}$, and Meltzer PS (2000). Detection of gene amplification by genomic hybridization to cDNA microarrays. Cancer Res 60:799-802.

Joos S, Haluska FG, Falk MH, Henglein B, Hameister $H$, Croce CM, and Bornkamm GW (1992). Mapping chromosomal breakpoints of Burkitt's $t(8 ; 14)$ translocations far upstream of c-myc. Cancer Res 52:6547-6552.

Joos S, Küpper M, Ohl S, von Bonin F, Mechtersheimer G, Bentz M, Marynen $P$, Möller $P$, Pfreundschuh $M$, Trümper L, and Lichter P (2000). Genomic imbalances including amplification of the tyrosine kinase gene JAK2 in CD30+ Hodgkin cells. Cancer Res 60:549-552.

Joos S, Otano-Joos MI, Ziegler S, Brüderlein S, du Manoir S, Bentz M, Möller P, and Lichter P (1996). Primary mediastinal (thymic) B-cell lymphoma is characterized by gains of chromosomal material including $9 p$ and amplification of the REL gene. Blood 87:1571-1578.

Joos S, Scherthan H, Speicher MR, Schlegel J, Cremer T, and Lichter P (1993). Detection of amplified DNA sequences by reverse chromosome painting using genomic tumor DNA as probe. Hum Genet 90:584-589.

Kallioniemi A, Kallioniemi OP, Sudar D, Rutovitz D, Gray JW, Waldman F, and Pinkel D (1992). Comparative genomic hybridization for molecular cytogenetic analysis of solid tumors. Science 258:818-821.

Kirchhoff M, Gerdes T, Maahr J, Rose H, Bentz M, Döhner H, and Lundsteen C (1999). Deletions below 10 megabasepairs are detected in comparative genomic hybridization by standard reference intervals. Genes Chromosomes Cancer 25: 410-413.

Klein CA, Schmidt-Kittler O, Schardt JA, Pantel K, Speicher MR, and Riethmüller G (1999). Comparative genomic hybridization, loss of heterozygosity, and DNA sequence analysis of single cells. Proc Natl Sci USA 96:4494-4499.

Knuutila S, Aalto Y, Autio K, Bjorkqvist AM, El-Rifai W, Hemmer S, Huhta T, Kettunen E, Kiuru-Kuhlefelt S, Larramendy ML, Lushnikova T, Monni O, Pere H, Tapper J, Tarkkanen M, Varis A, Wasenius VM, Wolf $M$, and Zhu $Y$ (1999). DNA copy number losses in human neoplasms. Am J Pathol 155:683-694.

Knuutila S, Bjorkqvist AM, Autio K, Tarkkanen M, Wolf M, Monni O, Szymanska J, Larramendy ML, Tapper J, Pere H, El-Rifai W, Hemmer S, Wasenius VM, Vidgren V, and Zhu Y (1998). DNA copy number amplifications in human neoplasms: Review of comparative genomic hybridization studies. Am J Pathol 152:1107-1123.

Koivisto P, Kononen J, Palmberg C, Tammela T, Hyytinen E, Isola J, Trapman J, Cleutjens K, Noordzij A, Visakorpi T, and Kallioniemi OP (1997). Androgen receptor gene amplification: A possible molecular mechanism for androgen deprivation therapy failure in prostate cancer. Cancer Res 57:314-319.

Kuukasjarvi T, Tanner M, Pennanen S, Karhu R, Visakorpi T, and Isola J (1997). Optimizing DOP-PCR for universal amplification of small DNA samples in comparative genomic hybridization. Genes Chromosomes Cancer 18:94-101.

Langer PR, Waldrop AA, and Ward DC (1981). Enzymatic synthesis of biotin-labeled polynucleotides: Novel nucleic acid affinity probes. Proc Natl Acad Sci USA 78:6633-6637.

Lichter P, Bentz M, and Joos S (1995). Detection of chromosomal aberrations by means of molecular cytogenetics:
Painting of chromosomes and chromosomal subregions and comparative genomic hybridization. Methods Enzymol 254: 334-359.

Lichter P, Joos S, Bentz M, and Lampel S (2000). Comparative genomic hybridization: Uses and limitations. Semin Hematol 37:348-357.

Lipshutz RJ, Fodor SP, Gingeras TR, and Lockhart DJ (1999). High density synthetic oligonucleotide arrays. Nat Genet 21:20-24.

Monni O, Joensuu H, Franssila K, and Knuutila S (1996). DNA copy number changes in diffuse large B-cell lymphomacomparative genomic hybridization study. Blood 87:52695278.

Otano-Joos M, Mechtersheimer G, Ohl S, Wilgenbus KK, Scheurlen W, Lehnert T, Willeke F, Otto HF, Lichter P, and Joos S (2000). Detection of chromosomal imbalances in leiomyosarcoma by comparative genomic hybridization and interphase cytogenetics. Cytogenet Cell Genet 90:86-92.

Pinkel D, Segraves R, Sudar D, Clark S, Poole I, Kowbel D, Collins C, Kuo WL, Chen C, Zhai Y, Dairkee SH, Ljung BM, Gray JW, and Albertson DG (1998). High resolution analysis of DNA copy number variation using comparative genomic hybridization to microarrays. Nat Genet 20:207-211.

Pollack JR, Perou CM, Alizadeh AA, Eisen MB, Pergamenschikov A, Williams CF, Jeffrey SS, Botstein D, and Brown PO (1999). Genome-wide analysis of DNA copy-number changes using cDNA microarrays. Nat Genet 23:41-46.

Quinn LA, Moore GE, Morgan RT, and Woods LK (1979). Cell lines from human colon carcinoma with unusual cell products, double minutes, and homogeneously staining regions. Cancer Res 39:4914-4924.

Reifenberger G, Ichimura K, Reifenberger J, Elkahloun AG, Meltzer PS, and Collins VP (1996). Refined mapping of 12q13-q15 amplicons in human malignant gliomas suggests CDK4/SAS and MDM2 as independent amplification targets. Cancer Res 56:5141-5145.

Schena M, Shalon D, Heller R, Chai A, Brown PO, and Davis RW (1996). Parallel human genome analysis: Microarraybased expression monitoring of 1000 genes. Proc Natl Acad Sci USA 93:10614-10619.

Schwab M, Varmus HE, Bishop JM, Grzeschik KH, Naylor SL, Sakaguchi AY, Brodeur G, and Trent J (1984). Chromosome localization in normal human cells and neuroblastomas of a gene related to c-myc. Nature 308:288-291.

Solinas-Toldo S, Lampel S, Stilgenbauer S, Nickolenko J, Benner A, Döhner H, Cremer T, and Lichter P (1997). Matrixbased comparative genomic hybridization: biochips to screen for genomic imbalance. Genes Chromosomes Cancer 20:399-407.

Stratowa C, Löffler G, Lichter P, Stilgenbauer S, Haberl P, Schweifer N, Döhner H, and Wilgenbus KK (2001). CDNA microarray gene expression analysis of B-cell chronic lymphocytic leukemia proposes potential new prognostic markers involved in lymphocyte trafficking. Int J Cancer 91:474-480.

Tanner MM, Tirkkonen M, Kallioniemi A, Isola J, Kuukasjarvi T, Collins C, Kowbel D, Guan XY, Trent J, Gray JW, Meltzer $P$, and Kallioniemi OP (1996). Independent amplification and frequent co-amplification of three nonsyntenic regions on the long arm of chromosome 20 in human breast cancer. Cancer Res 56:3441-3445. 
Telenius H, Pelmear AH, Tunnacliffe A, Carter NP, Behmel A, Ferguson-Smith MA, Nordenskjold M, Pfragner R, and Ponder BA (1992). Cytogenetic analysis by chromosome painting using DOP-PCR amplified flow-sorted chromosomes. Genes Chromosomes Cancer 4:257-263.

Weber T, Weber RG, Kaulich K, Actor B, Meyer-Puttlitz B, Lampel $S$, Büschges $R$, Weigel $R$, Deckert-Schlüter $M$, Schmiedek $P$, Reifenberger G, and Lichter P (2000). Characteristic chromosomal imbalances in primary central nervous system lymphomas of the diffuse large B-cell type. Brain Pathol 10:73-84.
Zitzelsberger $H$, Engert D, Walch A, Kulka U, Aubele $M$, Hofler H, Bauchinger M, and Werner M (2001). Chromosomal changes during development and progression of prostate adenocarcinomas. Br J Cancer 84:202-208. 